\title{
EXTENSÃO EM EDUCAÇÃO ESPECIAL: CONTRIBUIÇÕES PARA A FORMAÇÃO NAS LICENCIATURAS
}

\author{
EXTENSION IN SPECIAL NEEDS EDUCATION: CONTRIBUTIONS TO \\ TRAINING IN TEACHER UNDERGRADUATE COURSES
}

\author{
Nelma de Cassia Silva Sandes Galvão ${ }^{1}$
}

\begin{abstract}
RESUMO
O estudo apresenta e discute uma atividade de extensão universitária desenvolvida através de subprojeto do Programa de iniciação à docência (PIBID) na rede municipal de ensino de uma capital do Nordeste, com escolas de Educação Infantil, Ensino Fundamental I e II, contempladas por Salas de Recursos Multifuncionais (SRM). As SRM são espaços de Atendimento Educacional Especializado, implementados pelo Ministério da Educação e voltados para o trabalho de suporte a inclusão escolar de alunos público alvo da Educação Especial, a saber: alunos com deficiência, alunos com altas habilidades/superdotação, alunos com transtornos globais de desenvolvimento. As atividades de extensão envolveram 25 alunos de licenciaturas (pedagogia, história, letras, artes-plásticas), cinco professores da rede municipal, responsáveis por salas de recurso multifuncional das cinco escolas contempladas pelo projeto e um professor universitário. Este artigo tem como objetivo investigar limites e possibilidades deste subprojeto PIBID/Educação Especial para a formação do licenciando que atuará com os novos paradigmas da educação especial a partir da perspectiva da educação inclusiva. A metodologia consistiu em analisar as produções reflexivas de alunos envolvidos na realização da atividade de extensão, com foco na relação entre as práticas do PIBID como experiência formativa. Os resultados apontam que o estreitamento da relação entre a universidade e a escola ampliou o conhecimento sobre a educação especial, uma prática educacional escassa, quando não ausente, na formação dos licenciandos.
\end{abstract}

Palavras-chave: Extensão. Educação Especial. Formação inicial. Licenciaturas.

\begin{abstract}
The paper discusses an activity carried out under the scope of the so-called "Programme of Initiation to Teaching (PIBID) in local schools in a Northeastern State capital. Early Childhood Education and Elementary pupils attending classes at a multifunction room equipped to support disabling students, as well as high ability or severe global development. Extension activities involved 25 undergraduate students (from Pedagogy, History, Language and Arts and five public school teachers. The research aimed to investigate the limits and possibilities of the project to prepare future teachers to work within new approaches to special needs education. The methodology consisted of analyzing the undergraduate students production, as well as their personal observations, focusing on the relationship between the practices of PIBID as a formative experience. The results indicate that the strengthening of the relationship between the university and the school expanded the knowledge about special needs education, a relatively scarce educational practice in the teacher's education.
\end{abstract}

Keywords: Extension. Special Needs Education. Teacher Trainer. Undergraduate Courses.

\footnotetext{
${ }^{1}$ Universidade Federal da Bahia. Email: nelmasandes@yahoo.com.br
} 


\section{INTRODUÇÃO}

Este estudo se configura tendo como temática central as atividades de extensão que envolvem a Universidade e a Educação Básica, seus limites e possibilidades. Para tanto apresenta e discute as atividades desenvolvidas pelo subprojeto interdisciplinar, PIBID educação Especial, vinculado ao PROGRAMA INSTITUCIONAL DE APOIO A BOLSA DE INICIAÇÃO A DOCÊNCIA (PIBID), que vem sendo desenvolvido desde 2012, em escolas inclusivas da rede municipal de uma capital do Nordeste.

A Educação Especial é a modalidade educacional, que se ocupa de "assegurar a inclusão escolar de alunos com deficiência, transtornos globais do desenvolvimento e altas habilidades/superdotação" (BRASIL, 2008, p. 13), também nomeados como alunos com Necessidades Educacionais Especiais (NEE).

$\mathrm{Na}$ política educacional atual, as ações da Educação Especial são realizadas de uma perspectiva inclusiva, que orienta a inserção dos alunos público alvo da educação especial no sistema regular de ensino. Essa inclusão é regulamentada por uma legislação educacional específica que preconiza dentre outras coisas, a garantia de acesso do aluno com NEE a concomitância entre as ações do ensino regular e do ensino especializado. Sendo assim paralelo a inclusão escolar, o sistema educacional precisa oferecer o Atendimento Educacional Especializado (AEE) (BRASIL, 2010)

O AEE pode ser desenvolvido nas Instituições Especiais ou na escola regular. Quando nas escolas regulares, o AEE ocorre nas Salas de Recursos Multifuncionais (SRMs), espaço em que serão desenvolvidas "estratégias de aprendizagem, centradas em um novo fazer pedagógico que favoreça a construção de conhecimentos pelos alunos, subsidiando-os para que desenvolvam o currículo e participem da vida escolar" (ALVES, GOTTI, GRIBOSKI, DUTRA, 2006,p.18).

As SRMs, passaram a ser implementadas como política pública no ano de 2006 e funcionam com professores especializados em AEE que complementam ou suplementam as necessidades educacionais especiais dos alunos com NEE, no turno oposto em que ocorrem as suas aulas regulares. De maneira geral as salas são montadas considerando duas configurações: do tipo 1 com recursos materiais para que possam servir para o AEE de todos alunos com NEE; e a do tipo 2 com recursos materiais para os alunos com deficiência visual.

É fato, que as mudanças que estão sendo suscitadas, envolvem a relação professoraluno, mas também novas configurações nas unidades de ensino e no sistema educacional. A 
prática da inclusão escolar no Brasil é relativamente nova. As políticas públicas educacionais voltadas para esta realidade ainda estão em fase de implantação e os resultados são validados considerando-se dados quantitativos referentes ao número de matrícula dos alunos. Os dados qualitativos, que poderiam constar nas pesquisas sobre a temática, são ainda escassos e com ênfase na socialização do aluno (BUENO, 2006).

É fundamental, portanto, que as práticas pedagógicas inclusivas saiam da indefinição e se transformem em ação real e concreta, seja na legislação, na pesquisa, ou no cotidiano da sala de aula, tanto pela importância que a escola tem para o desenvolvimento da pessoa, como pelo que ela representa como instituição social. Investir na formação, inicial e continuada, do educador pode ser um importante suporte para a concretização da escola inclusiva.

Visando atuar nesta perspectiva formativa durante o ano de 2012 e 2013, foi desenvolvido um subprojeto PIBID interdisciplinar no âmbito da Educação Especial envolvendo vinte e cinco alunos licenciandos, dos cursos de Pedagogia, História, Letras e Artes Plásticas; e cinco professores municipais responsáveis por salas de recurso multifuncionais de cinco escolas da rede, sendo quatro de Educação Infantil e Ensino Fundamental I e uma do Ensino Fundamental I e II; e uma professora universitária coordenadora do referido projeto e autora deste presente artigo. O objetivo do projeto foi através de atividades de extensão universitária, apoiar de forma interdisciplinar ações dos professores especialistas em AEE, oportunizando aos alunos das Licenciaturas conhecerem e vivenciarem práticas de docência relacionadas às especificidades comunicativas dos alunos com NEE.

\section{A INTERSECÇÃO ENTRE SABERES E FAZERES: A UNIVERSIDADE E O CHÃO DA ESCOLA}

$\mathrm{Na}$ atualidade, o campo da formação de professores, tanto na sua dimensão inicial como na sua dimensão continuada, aponta para o diálogo entre a Universidade e realidade concreta da educação brasileira, estreitando as relações entre a teoria e a vivência real com a escola (FERREIRA, 2012; BRASILEIRO, 2008).

No projeto em foco, subprojeto PIBID/Educação Especial, a interface entre a teoria e prática se concretiza, quando o aluno em formação inicial, se aproxima da sua prática profissional e pode: ampliar o seu conhecimento sobre a prática docente na área da Educação Especial, contextualizando de forma atualizada as possibilidades e desafios do ensino aos 
alunos com Necessidades Educacionais Especiais; desconstruir os mitos sobre a aprendizagem e desenvolvimento do aluno com Necessidades Educacionais Especiais; realizar estudos reflexivos sobre a política do Atendimento Educacional Especializado implementada na rede regular de ensino da cidade onde ocorre a pesquisa, com produções acadêmicas sobre a temática, com ênfase na comunicação dos alunos com NEE acompanhados durante o projeto. A ênfase que o referido projeto de extensão atribui à comunicação, se justifica nas escolhas teóricas que sustentam a estruturação do mesmo e que passam a ser explicitadas.

Entendendo que a aprendizagem se dá com e no ambiente cultural onde a criança está inserida, impulsionando nessa dialética o desenvolvimento interior ou intrapsicológico do ser humano (VIGOTSKY, 1994), torna-se fundamental estimular a comunicação dentro do espaço escolar, ressignificar as situações, atenuando e derrubando as barreiras pedagógicas e atitudinais.

A comunicação é ativa, intencional e desejada, e para se estabelecer pressupõe, por parte dos interlocutores (quem envia e quem recebe), um processo de análise e comparação das mensagens por eles produzidas. Este processo envolve uma "negociação de significados" em comum, ou seja, para analisar uma mensagem, o signo utilizado por quem o produziu deve ser entendido por quem o recebe. A negociação é considerada por Viñas (2004) como a base da interação comunicativa, e, portanto, do processo de comunicação, nesta negociação as barreiras interacionais precisam ser superadas.

Para Vigotsky (1994, p. 33), “[...] o momento de maior significado no curso do desenvolvimento intelectual [...] acontece quando fala e a atividade prática, então duas linhas completamente independentes de desenvolvimento, se convergem." Quando o pensamento e a fala se transformam em pensamento verbal, as coisas recebem nome; as palavras começam a ter significado e paulatinamente a esses significados vão se acoplando sentidos construídos ao longo da vida, a partir das relações afetivas da criança com o mundo.

É interessante observar que, ao mesmo tempo que as crianças se utilizam das mãos e dos instrumentos para agir sobre o mundo, também usam a linguagem (signos). No início da infância, a fala e a atividade prática se juntam formando um amálgama. Assim, é a partir do surgimento do "pensamento verbal", juntamente com a "linguagem intelectual", que o homem passa a ter um modo de funcionamento psicológico mais sofisticado, envolvendo a mediação dos símbolos criados pela linguagem. 
A linguagem, enquanto signo, tem uma função reguladora que se faz presente nos processos cognitivos de internalização do sujeito, e que retorna ao ambiente modificada pela elaboração feita internamente. Vigotsky (2008) faz a analogia desse processo com uma espiral, onde os conhecimentos vão sendo adquiridos na relação com o meio, internalizados e, após a elaboração junto a aprendizados preexistentes, retornam ao ambiente modificando o mesmo, favorecendo uma nova situação modificadora para o indivíduo, de modo a estimulálo para que se desenvolva sempre mais, de forma dialética. É uma evolução psicológica e cultural vinculada diretamente aos processos de ensinar e aprender e, por isso, constituem um fenômeno para ser observado e entendido também no ambiente escolar.

É através da linguagem que os seres humanos podem trocar informações acerca de si e do mundo, cada vez mais ampliando a compreensão do que o circunda. As diferenças entre o homem e os primatas são finalmente estabelecidas quando o pensamento passa a ser verbal e a linguagem racional. Ao adquirir a linguagem, aspecto próprio e inerente à espécie, o ser humano se diferencia dos outros animais, o biológico torna-se sócio-histórico (VIGOTSKY, 2008).

Um outro aspecto da linguagem apontado por Vigotsky (2008) e Viñas (2004) referese ao fato de que a linguagem não é apenas um sistema que envolve a relação com o mundo, mas também uma forma de comunicar-se consigo mesmo, organizar os pensamentos, conhecer a subjetividade, dar sentido às sensações, etc.

As concepções baseadas na teoria sócio-histórica, cuja abordagem privilegia a forma como a linguagem se estrutura e como os pensamentos mais elaborados se organizam - a exemplo de Viñas, estudiosa da educação especial na área da comunicação das pessoas com surdocegueira -, encontram respaldo em outros autores. Reily se coloca nesta linha de estudos no campo da educação especial e tem, na teoria sócio-histórica, um referencial, conforme se pode observar:

\footnotetext{
A linguagem integra e constitui a cultura de qualquer sociedade. A língua tem forte papel na constituição da identidade de uma sociedade e a escrita da língua, por sua vez, promove a formação da memória cultural. Da mesma maneira, vivendo em sociedade, a linguagem se faz vital e se consolida nas interações. (REILY, 2004, p. 15).
}

Aprende-se uma linguagem e insere-se no sistema formal de uma língua quando se vive em comunidade, é o que confirma Reily, segundo o fragmento acima citado. A escola é uma comunidade onde coexistem diversos atores, e estes se situam não apenas no espaço da 
escola, mas inclusive fora dela, nos diversos contextos de desenvolvimento com os quais os diversos atores interagem, como descrito por Bronfenbrenner (1996). A escola, concebida como um sistema de relações, necessita que a comunidade escolar, e não apenas o professor, se prepare para lidar com o que ocorre no cotidiano da sala de aula (PATTO, 1999). É fundamental fomentar, no ambiente escolar, a cultura do acolhimento à diversidade, promover situações de apreciação e acomodação da complexidade sócio-cultural dos seres humanos, trazer para as instâncias internas da escola, de forma crítica e contextualizada, o que acontece nos outros contextos em que a criança circula, ajudando-a a superar barreiras que as vivências extraescolares possam representar para o cotidiano escolar (SACRISTAN, 2002).

Neste projeto, apresentado por este artigo, os bolsistas atuando como tutores que apóiam a comunicação dos alunos com NEE desenvolveram atividades relativas à adaptação das diferentes linguagens usadas na escola: suplementação das informações impressas considerando outras formas de expressão gráfica além da leitura e escrita convencional;complementação das informações visuais e auditivas adaptando o material do aluno considerando as dimensões estéticas, tácteis e auditivas, favorecendo o entendimento dos alunos com NEE. Enfim, contribuíram como mediadores para a aprendizagem e desenvolvimento dos alunos com NEE acompanhados.

A lógica da prática inclusiva, vivida por bolsistas e alunos, aponta diferentes interfaces de uma escola inclusiva, revelando que não se trata apenas de uma prática pedagógica diferente, mas de um novo paradigma educacional que envolve "[...] ação política, cultural, social e pedagógica" (BRASIL, 2008, p. 2). O papel da interação Universidade e Educação Básica é magnificado, por diferentes contextos que se interpõem, sendo em alguns momentos indissociáveis o vivido no cotidiano dentro e fora da escola. Nessa dimensão, na atualidade o papel da educação básica e da universidade é de superar a lógica da exclusão e construir sistemas escolares inclusivos de fato.

\section{NOVAS PERSPECTIVAS EDUCACIONAIS: O PARADIGMA INCLUSIVO}

A lógica da exclusão, todavia, transparece na naturalização do "fracasso escolar", nos processos normativos de distinção dos alunos por "“...] características intelectuais, físicas, culturais, sociais e linguísticas, entre outras, estruturantes do modelo tradicional de educação escolar" (BRASIL, 2008). Na atualidade, pesquisar sobre a escola, principalmente escola para alunos de baixa renda, é constatar a realidade excludente que crianças e adolescentes vivem, 
sem merenda escolar suficiente, sem acesso ao básico do material escolar necessário, sem apoio para as suas necessidades de saúde, entendendo a saúde no seu aspecto bio-psico-social, sem que de fato sejam consideradas as diferenças em seus tantos níveis (ou desníveis). Quando se pensa em uma escola inclusiva, há que se observar todos estes aspectos que atravessam a prática escolar e que são fatores de risco para a educação de qualquer criança, mas podem potencializar os desafios de uma prática inclusiva voltada a alunos com necessidades educacionais especiais, vez que a eles se agregam as questões das limitações físicas, auditivas, visuais, e etc.

Para pensar em uma escola inclusiva, é necessário desnaturalizar ideias como a de que o "fracasso escolar" é algo esperado e inevitável para os alunos de baixa renda que frequentam escolas periféricas e/ou públicas. Para agir favoravelmente em direção à implementação de uma escola inclusiva, é necessário entender que a ação não se restringe apenas à sala de aula, ao professor e ao aluno, mas transcende o espaço escolar, influencia e sofre influência de vários outros sistemas. Diante disso, pressupõe uma mudança estrutural do paradigma onde se sustenta a prática pedagógica na atualidade, marcado predominantemente pela massificação das informações, por uma lógica excludente que busca homogeneizar as ações pedagógicas, alienando do processo educacional aqueles que não se encaixam nos padrões.

Fomentada pelo estudo de documento publicado pelo Ministério da Educação (BRASIL, 2008), a reflexão aponta que, com a educação inclusiva, há melhores chances de que ocorra a reestruturação do ensino regular e da educação especial, partindo da ideia de que "[...] escolas regulares com orientação inclusiva constituem os meios mais eficazes de combater atitudes discriminatórias" (BRASIL, 2008, p.15). Esses espaços de aprendizagem são um local por excelência para todas as pessoas, tendo elas necessidades educacionais especiais ou não.

Para que os resultados sejam satisfatórios, a Educação especial deve se organizar para, nos termos da lei e da responsabilidade, atender as especificidades do aluno na escola, fomentar redes de apoio, desenvolver formação continuada para os professores e comunidade escolar. As atividades a serem desenvolvidas pela educação especial devem ser de complementação e/ou suplementação ao ensino comum, cujos exemplos são os programas de enriquecimento curricular, ensino das linguagens e códigos de comunicação e uso da tecnologia assistiva (BRASIL, 2010). 
É assegurada a presença do atendimento educacional especializado (AEE) em todas as etapas e modalidades de ensino. Dá-se ênfase à estimulação precoce na faixa etária de 0 a 3 anos; nas demais faixas etárias deve o AEE se constituir como uma obrigatoriedade a ser assegurada pelo sistema de ensino, considerando também a educação voltada ao indígena, o camponês e o quilombola. Finalmente, qualquer ação pedagógica deve prever o AEE.

Para além da estimulação precoce, alguns destaques são dados a outras práticas diferenciadas, como: a) educação bilíngue para o deficiente auditivo usuário de Libras, garantindo-lhe o direito de ter acesso à língua portuguesa e a LIBRAS, sendo a língua portuguesa a segunda língua dos surdos, com ênfase na convivência entre surdos na escola regular, significando que o aluno deve ter oportunidade de, na própria escola regular, conviver com colegas também surdos; b) garantia do instrutor, tradutor/intérprete de LIBRAS, guiainterprete, monitor ou cuidador de alunos com necessidades de apoio nas atividades de vida autônoma.

Quanto às orientações emitidas para a formação de professores para trabalhar com os alunos público alvo da Educação Especial, pontos de dubiedade em documento emitido pelo MEC (BRASIL, 2008), destacam-se. Por não ser precisa, a orientação dá margem à interpretação de tratar-se de um professor generalista que deverá dar conta de todas as especificidades, indo de encontro ao próprio documento que, em outro parágrafo, orienta que o AEE deve ser realizado mediante a atuação de profissionais com conhecimentos específicos. Cria-se assim lacunas quanto a ações mais pontuais no que diz respeito a formação desses educadores.

\section{A FORMAÇÃO PARA A EDUCAÇÃO ESPECIAL NA PERSPECTIVA INCLUSIVA}

Pesquisas na área da Educação Especial, com foco na formação de professores, apontam como o tecnicismo em si, ou seja, a teoria apenas, não é suficiente para uma atuação eficaz com o aluno com Necessidades Educacionais Especiais. Costa (2010, p.125), a partir de pesquisa com professores no Estado do Rio de Janeiro afirma que "ao focar em técnicas, o professor não consegue desenvolver a sua sensibilidade, não percebendo nos alunos com deficiência nada para além da aparência”. A autora resgata da fala de professores que ao reconhecer nos seus alunos com NEE, as possibilidades, os desafios impostos por um tecnicismo reducionista e tradicional, são superados, podendo o professor pensar e efetivar práticas pedagógicas mais inclusivas. 
$\mathrm{Na}$ realidade do projeto PIBID/Educação Especial, identificou-se uma situação similar, na qual os bolsistas envolvidos qualificam como positivas as oportunidades que tem tido de atrelar teoria e prática, com especial destaque para a possibilidade que tem com o projeto, de refletir sobre o que fazem e socializar com academia as suas construções teóricas:

Vale salientar que através do PIBID foi possível escrever trabalhos acadêmicos e participar de eventos para apresentar tais trabalhos, isso foi muito relevante para minha formação acadêmica.Portanto, posso afirmar que participar como bolsista do PIBID é um diferencial na minha formação inicial, pois antes eu conhecia apenas as teorias voltadas para educação inclusiva, agora posso refletir as teorias junto à prática. (BARROS, et.al,2013,s/p)

Crochìk (2012, p.58), refletindo sobre a presença da Educação Especial como uma prática de inclusão escolar, também traz aspectos referentes a sensibilidade humana para além das diferenças:

[...] a educação inclusiva tem se introduzido com força em nosso meio,o que indica uma sociedade que busca cada vez mais um convívio amplo e perene entre seus membros, convívio este marcado pela identificação com o que há de mais frágil nos homens e, dessa forma, permite a existência da diversidade que implica simultaneamente a singularidade e a universalidade: a possibilidade de cada um se reconher no que lhe é distinto, considerando-o como representante da humanidade e por isso de si mesmo.

Nessas perspectivas, a escola, o espaço da sala de aula, são concebidos como um sistema de relações, necessitando que a comunidade escolar, e não apenas o professor, se prepare para lidar com o que ocorre no cotidiano da sala de aula (PATTO, 1999). É fundamental fomentar, no ambiente escolar, a cultura do acolhimento à diversidade, promover situações de apreciação e acomodação da complexidade sócio-cultural dos seres humanos, trazer para as instâncias internas da escola, de forma crítica e contextualizada, o que acontece nos outros contextos em que a criança circula, ajudando-a a superar barreiras que as vivências extraescolares possam representar para o cotidiano escolar.

A respeito dessas barreiras, Miranda (2008, p. 292) faz a seguinte reflexão:

Parece evidente a existência de barreiras no cotidiano da sala de aula, que dificultam o processo de interação e de aprendizagem dos diferentes alunos. Essas barreiras são pedagógicas quando se referem às condições para construção do conhecimento no âmbito da escola e atitudinais quando são relativas às interações sociais e se relacionam diretamente com os aspectos pedagógicos, influenciando-se mutuamente. 
Para superar estas barreiras é necessário inicialmente, que se possa identificá-las, nesse sentido um conhecimento mais específico sobre a Educação Especial pode ser de grande ajuda. Autoras como Souza, Duboc, Santos (2011), Pimentel (2012) ao refletirem sobre a formação de professores na perspectiva da educação inclusiva, apontam a fragilidade da formação inicial e continuada, enfatizando que é necessário um maior investimento neste processo formativo, creditando a esta ação, possibilidades de uma inclusão escolar mais eficaz, que promova de fato a aprendizagem do aluno com NEE.

As bolsistas do PIBID/Educação Especial ao construírem um texto reflexivo sobre como as experiências com esta atividade de extensão universitária estão repercutindo na sua formação como educadores revelam:

Com o programa foi possível conhecer as crianças com as diversas NEE, o AEE como um espaço dentro da escola que visa á melhoria da aprendizagem das crianças com NEE, as práticas pedagógicas propostas pela professora responsável da SRM, e também apresentar minhas propostas de intervenções a ser realizadas com os alunos. Outro ganho importante foi à participação nas atividades formativas organizadas pelas bolsistas e coordenadora do subprojeto. Essas estratégias de formação me proporcionaram mais compreensão e reflexão acerca da educação inclusiva.. (BARROS, et.al,2013,s/p)

Os educadores em formação, evidenciam que apesar de serem espaços físicos diferentes, a escola, a universidade, os grupos sociais vêm por estabelecer entre si uma rede de relações, e as experiências daí advindas possibilitam que aquilo que o aluno vive na escola, ou traz da Universidade ou leva para Universidade, e assim revive suas experiências em qualquer outra situação/contexto social.

Martinez (2009, p. 172), ao falar sobre o espaço escolar, aborda questões que, presentes na dinâmica de uma escola, complementam a ideia das relações que podem ser estabelecidas entre os ambientes e entre as pessoas que os integram:

Por sua vez, a ação dos sujeitos nesse espaço social contribui para a configuração subjetiva que este assume, estabelecendo-se uma relação recursiva entre subjetividades individuais e subjetividade social. Os sistemas de relações que se dão entre os membros da instituição, os estilos de gestão, os valores, as normas, e o clima emocional, constituem apenas alguns exemplos de importantes fatores que influem, direta ou indiretamente, não apenas os modos de agir dos integrantes do coletivo escolar, mas também, os seus estados emocionais, a sua satisfação com a instituição e o seu compromisso e motivação com as atividades que realizam. 
O que nos afiança Martinez, portanto, é a existência das diversas influências diretas ou indiretas atuando sobre o coletivo escolar. Brofenbrenner (1996) também se refere a estas influências e, na proposta de aprofundar a questão, nomeia o ambiente onde o ser humano está inserido como "ecológico" e organiza-o em níveis de interação uns com os outros, sendo que o nível mais interno seria aquele que contém a pessoa em desenvolvimento. É "[...] um local onde as pessoas podem facilmente interagir face a face - casa, creche, playground e assim por diante" (BRONFENBRENNER, 1996, p.19). A escola, portanto, é um ambiente de interação face a face, onde relações de intensa proximidade podem ocorrer entre as pessoas.

Pode-se inferir, a partir das questões apontadas, que a pessoa, enquanto ser único e singular, desempenha papéis que são construídos na sua interação com outras pessoas, nos diversos ambientes com os quais interage. Deve-se levar em conta que esta interação pode ser direta, face a face, presencial ou não. Fica evidente a rede de significações que vai atravessando o cotidiano de uma sala de aula, de uma escola dando forma ao papel que o licenciando em sua formação inicial, o professor e os alunos da classe irão desempenhar enquanto pessoas em desenvolvimento, convivendo em um ambiente face a face. Exemplo disso é o relato da bolsista PIBID do subprojeto Educação Especial:

Como bolsista do subprojeto PIBID Educação Especial posso falar com propriedade do quanto o mesmo tem me possibilitado uma formação diferenciada, principalmente no que se refere à Educação Especial. Estar inserida em uma escola inclusiva, com alunos público alvo da inclusão, tudo isso, tem atenuado o distanciamento entre a teoria e a prática, melhorando assim, o processo de formação dos bolsistas envolvidos nesse subprojeto. Participar diretamente das atividades desenvolvidas na Sala de Recursos Multifuncionais, na qual faz-se presente uma diversidade de alunos, todos com suas especificidades, tem sido um ganho imensurável, uma vez que esse contato tem me permitido conhecer cada aluno, suas necessidades e seus potenciais. E a partir desse contato, nós graduandos temos mais convicção de que todos os alunos com necessidades educacionais especiais são capazes de avançar no seu processo de aprendizagem, desde que nós educadores estejamos cada vez mais preparados para atuar em prol de uma educação que respeite as diferenças, e acima de tudo, promova práticas educativas que possibilite que todos aprendam. (BARROS ET AL, 2013, $\mathrm{s} / \mathrm{p})$

$\mathrm{Na}$ fala da bolsista, licenciando de pedagogia, pode-se perceber a construção reflexiva a partir de uma vivência em rede, conectada com a escola real, o ambiente de fato, o ambiente imediato onde acontece o fenômeno do ensino e eaprendizagem. Segundo Lisboa e Koller (2004, p. 338), “[...] o ambiente imediato é fundamental para a compreensão de todo o desenvolvimento posterior, pois é palco para as mais simples e primitivas, até as mais 
complexas relações que o ser humano é capaz de estabelecer". Na sala de aula, novas relações se iniciam, ou antigas concepções se mantêm; papéis podem ser construídos ou reeditados; o novo e o antigo dialogam, passíveis de serem reinventados na dinâmica das tarefas cotidianas, dos avanços, retrocessos e desafios.

Martinez (2009, p. 172) destaca a dimensão psicossocial da escola para além da função ensino e aprendizagem, ao afirmar: "Enxergar a escola não apenas como um lugar onde uns ensinam e outros aprendem, mas como um espaço social sui generis no qual as pessoas convivem e atuam, implica reconhecer a importância da sua dimensão psicossocial”.

No cotidiano, a criança, ao internalizar conceitos (que é uma atividade intrapsíquica), o faz relacionando com aprendizagens oriundas das suas interações sociais, das experiências vividas, a partir de construções interpsíquicas, porque esses processos não são estanques, mas dinâmicos, atuam impulsionando aprendizagens possíveis. É pertinente afirmar, portanto, a importância da convivência social para o processo de aprendizagem.

Segundo Vigotsky (1994, p. 101):

[...] o aprendizado não é desenvolvimento; entretanto, o aprendizado adequadamente organizado resulta em desenvolvimento mental e põe em movimento vários processos de desenvolvimento que, de outra forma, seriam impossíveis de acontecer. Assim, o aprendizado é um aspecto necessário e universal do processo de desenvolvimento das funções psicológicas, culturalmente organizadas e especificamente humanas.

Apesar de atrelado à integridade das condições individuais, orgânicas e genéticas, o desenvolvimento não ocorre sem que o aprendizado possa despertar os processos internos, intrapsicológicos, que atuam no desenvolvimento.

De acordo com Vigotsky (1994), a instrução formal - escola/professor -, quando garante uma comunicação eficaz, favorece a aprendizagem no ambiente imediato, onde o desenvolvimento ocorre de forma mais direta, atuando assim na zona de desenvolvimento proximal da criança. Sobre este ambiente face a face, não se pode ignorar que o mesmo é influenciado por outros contextos. Souza e Rocha (2008) reforçam esta ideia quando colocam que a escola é uma organização atravessada por instituições que representam padrões, hábitos e papéis escolhidos como válidos pela comunidade escolar. Essa influência não é neutra, porém marcada por interesses pessoais, políticos e públicos, e influencia e sustenta uma rotina institucional, naturalizando e referenciando os atos cotidianos da escola. Assim se expressam as autoras: 
Uma escola organiza seu cotidiano de trabalho, afirma referenciais de normalidade, de certo e errado, de "quem sabe" e de "quem não sabe e deve aprender", de "como deve se comportar". Afirma valores, modos, tempos e marca lugares, classifica e impõe certa ordem, ao mesmo tempo que cria o que escapa, o que é avesso, o que é desordem. (SOUZA; ROCHA, 2008, p. 39 , grifos do autor).

Esse processo de normalidade por vezes institui o diferente, o que é avesso, um lugar de anormalidade, e pode estabelecer esse lugar a apenas uma pessoa ou a um grupo, que passa a ser entendido como elemento destoante do sistema escolar. As autoras então perguntam: " $\mathrm{O}$ que é o diferente? A princípio, poderíamos dizer que é 'o esquisito', 'o aluno especial', 'o que foge muito ao padrão estabelecido' como bom" (SOUZA; ROCHA, 2008, p. 42, grifos do autor). Com esta visão da diferença centrada em um indivíduo, ou em um grupo específico, a complexidade do cotidiano escolar fica reduzida a alguns alunos, ignorando-se que as "esquisitices", na verdade, fazem parte de cada um de nós, de todos os seres humanos. O indivíduo (de igual modo os grupos "diferentes"), quando apartado do todo, torna-se depositário do que ocorre de errado no sistema escolar, erguendo-se em seu entorno diversas barreiras interativas que tendem a dificultar a sua aprendizagem e seu desenvolvimento.

No caso da educação da pessoa com NEE, Masini (2002, p. 79) ressalta:

É necessário ao educador dispor de engenho, paciência e energia. Engenho para propiciar práticas à criança, para explorar o meio circundante e comunicar-se com as pessoas, utilizando para isso os sentidos e os recursos que dispõe. Quando a situação oferece condições e o educador (tatilmente, visualmente, ou auditivamente) confirma-a, reconhecendo aquilo que ela está manifestando, ela [a criança] se sente à vontade e espontânea no uso de seus sentidos e dos próprios recursos.

A autora enfatiza ainda a importância da paciência, do respeito ao ritmo da criança, e do persistente estímulo, por parte do professor, no enfrentamento dos obstáculos cotidianos.Cabe questionar se a escola como está organizada na contemporaneidade dá sustentação a uma prática escolar realmente inclusiva. Anache (2007, p. 214), refletindo sobre os "muros" que se erguem no espaço escolar, afirma:

A frase "quebrar muros" sugere que há necessidade de mudanças na concepção de sujeito, de educação, de sociedade e, consequentemente, de uma outra forma de compreender o processo de aprendizagem e de desenvolvimento. (Grifos do autor). 
A autora apresenta, como um dos grandes desafios da Educação do Século XXI, "quebrar os muros" e caminhar em direção a uma educação que acolha a diversidade humana. Confirma a existência de uma falta de clareza sobre quais são de fato as lacunas dos estudantes considerados com necessidades educacionais especiais (NEE). Os documentos legais preconizam que esses alunos com NEE devem estar na escola regular, mas a prática é confusa, tanto na escola regular como nos espaços de educação especial que deveriam apoiar essa prática.

A falta de definição é reflexo de uma sociedade que segrega, exclui e quer incluir. A própria ideia de educação especial é um argumento para enquadrar um aluno com NEE e depois inclúi-lo em alguma modalidade de apoio especializado, o que, para Anache (2007, p. 217), seria retomar a ideia de que "[...] a necessidade especial recai no aluno e não na relação entre ele e as condições concretas de ensino e aprendizagem. Se a educação é inclusiva, qual a necessidade de enquadramento?".

Sobre a escola inclusiva, onde de fato ocorre uma "pedagogia para a inclusão", Miranda (2008, p. 296) lembra a importância de se evitar “[...] estabelecer separações e divisões estanques do conhecimento, dos espaços e dos papéis sociais de alunos e professores". A autora ainda aponta a necessidade da flexibilidade nas propostas curriculares, apostando no diálogo, na negociação entre professor e aluno, em busca de acessibilidade atitudinal que possa gerar e nutrir uma aprendizagem de fato significativa.

\section{CONCLUSÃO}

Quando a Universidade desconhece o que se passa na escola, acaba por disponibilizar uma formação insuficiente para os licenciandos, que no âmbito da Educação Especial, recorte deste artigo, pode significar um atendimento educacional especializado de pouca eficácia, não efetivando a inclusão escolar dos alunos com NEE. Assim sendo, o estreitamento das relações entre os saberes e os fazeres neste contexto educacional, a disseminação das informações sobre as políticas educacionais e a construção de práticas educacionais conjuntas, envolvendo o chão da escola e o saber acadêmico, podem ajudar na preparação de professores e profissionais da área da educação.

Os estudos apontam que é necessário construir uma política pública cada vez mais eficaz no que diz respeito à formação dos futuros educadores. Neste artigo foi apresentado e discutido, como as práticas formativas que envolvem ações de extensão universitária podem 
ser um importante recurso para apoiar o discente universitário na construção de uma prática profissional atual, critica e reflexiva. Possibilitando assim, que ocorram ações assertivas no interior das escolas, dando maior visibilidade ao potencial dos novos rumos da educação especial, cada vez mais inclusiva.

\section{REFERENCIAS}

AlveS, D. O; GOTTI M. O; GRIBOSKIC, M.; DUTRA, C. P. Sala de recursos multifuncionais: espaços para atendimento educacional especializado/elaboração. Brasília: Ministério da Educação, Secretaria de Educação Especial, 2006.

ANACHE, A. A. A pessoa com deficiência mental entre os muros da educação. In: CAMPOS, H. R. Formação em psicologia escolar: realidades e perspectivas. Campinas (SP): Alínea, 2007. p. 30-46.

BARROS, D.R.F.; SANTOS, M.P.J; SANTOS, M.P; AMARAL, S.S.; LIMA,V.N. PIBID UFBA e formação inicial docente: uma experiência com a educação inclusiva. In: V SEMINÁRIO PIBID/UFBA: inicialização a docência: o que temos feito? Disponível em: $<$ http://www.seminariopibid.ufba.br> Acesso em: 24 de abril de 2013.

BRASIL Ministério de Educação e Cultura. Política Nacional de Educação Especial na perspectiva da educação inclusiva. Brasília, 2008. Disponível em: $<$ http://portal.mec.gov.br/arquivos/pdf/politicaeducespecial.pdf $>$. Acesso em: 14 Dez. 2008.

Ministério de Educação e Cultura. Secretaria de Educação Especial. Nota Técnica $\mathrm{SEESP} / \mathrm{GAB} / \mathrm{N}^{\mathrm{o}}$ 11/2010. Brasília, 07 de maio de 2010. Disponível em: $<$ http://portal.mec.gov.br/arquivos/pdf/politicaeducespecial.pdf $>$. Acesso em: 18 de dezembro, de 2011.

BRASILEIRO, T. S. A. A formação do/a educador/a através da colaboração interinstitucional universidade/escola In: MELO, M.A.(org.) Desafios pedagógicos: na formação e trabalho docente e na avaliação São Luís: EDUFMA, 2008. 
BRONFENBRENNER, U.; CECI, S. J. A ecologia do desenvolvimento humano: experimentos naturais e planejados. Tradução de Maria Adriana Veríssimo Veronese. Porto Alegre: Artes Médicas, 1996.

BUENO, J. G. S. Alunos e alunos especiais como objeto de investigação: das condições sociais às condições pessoais adversas. In: Desigualdade social e diversidade cultural. FREITAS, M. C. (Org.). São Paulo: Cortez, 2006. p. 333-359.

COSTA, V.A. Educação inclusiva-para que? Experiências na escola pública In: SILVA M.G.; CARVALHO, M. B. W. B. Faces da inclusão. São Luiz: EDUFBA, 2010.

CROCHÍK J. L. Educação inclusiva e preconceito:desafios para a prática pedagógica In: MIRANDA T. G.; GALVÃO FILHO T. A. (org.) O professor e a educação inclusiva: formação, prática e lugares. Salvador: EDUFBA, 2012

FERREIRA, R. A. Formação de professores: um desafio sempre atual In: PIMENTEL, A.; CUNHA, M. C. Palavras entre cruzadas; escrito de formação de professores. Salvador: EDUFBA, 2012

LISBOA, C.; KOLLER, S. H. O microssistema escolar e os processos proximais: exemplos de investigações científicas e intervenções práticas. In: KOLLER, S. H. (Org.). Ecologia do desenvolvimento humano: pesquisa e intervenção no Brasil. São Paulo: Casa do Psicólogo, 2004. p. 337-354.

MARTINEZ, A. M Psicologia Escolar e Educacional: compromissos com a educação brasileira. Revista Semestral da Associação Brasileira de Psicologia Escolar e Educacional (ABRAPEE), n.1, Jan.-Jun. 2009. Vol.13, p.169-177.

MASINI, E. F. S. Do sentido, pelos sentidos, para o sentido. Niterói: Intertexto, 2002.

MIRANDA, T. G. Acessibilidade da pessoa com deficiência para a construção de uma escola inclusiva; o currículo e a interação. In: BAPTISTA, C. R.; CAIADO, K. R. M.; JESUS, D. M. Educação e pluralidade. Porto Alegre: Mediação, 2008. p. 291-301. 
PATTO, M. H. S. A produção do fracasso escolar: histórias de submissão e rebeldia. São Paulo: Casa do Psicólogo, 1999.

PIMENTEL, S.C. Formação de professores para a inclusão:saberes necessários e percursos formativos In: MIRANDA T. G.;GALVÃO FILHO T. A. (org.) O professor e a educação inclusiva: formação,prática e lugares. Salvador: EDUFBA, 2012

REILY, L. Escola Inclusiva: linguagem e mediação. Campinas: Papirus, 2004.

SACRISTAN, J. G. Educar e conviver na cultura global: as exigências da cidadania. Porto Alegre: Artmed, 2002.

SOUZA, L.R.; DUBOC, M.J.O. SANTOS, M.C. Proposições para a formação de professores na perspectiva da educação inclusiva In: BARZANO L. ARAÚJO, M.L. H.S. Formação de professores: retalhos de saberes. Feira de Santana: UEFS Editora, 2011.

SOUZA, M. P. R.; ROCHA, M. L. Políticas Educacionais: legislação, formação profissional e participação democrática. In: CONSELHO FEDERAL DE PSICOLOGIA. Ano da Psicologia na Educação: Textos Geradores. Brasília (DF), 2008. p. 27-52.

VIGOTSKY, L. S. A formação social da mente. São Paulo: Martins Fontes, 1994.

. Pensamento e Linguagem. São Paulo: Martins Fontes, 2008.

VINÃS P. G. La educación de las personas sordociegas. Diferencias y proceso de mediación. In: REYES D. A. La sordoceguera: um análisis multidisciplinar. Madrid: ONCE, 2004.

\section{RECEBIBO EM: 19/09/2013}

APROVADO PARA PUBLICAÇÃO EM: 14/09/2015 